\title{
Uso de mapas conceituais na disciplina de Cálculo Diferencial e Integral 1: uma estratégia em busca da aprendizagem significativa
}

\begin{abstract}
Edinéia Zarpelon
Luis Mauricio Martins de Resende

Nilcéia Aparecida Maciel Pinheiro

Resumo

Inevitavelmente as relações entre educação, sociedade e instituições de ensino englobam questões conflitantes como a reprovação. Em particular, na busca pela compreensão do fenômeno da reprovação no Cálculo Diferencial e Integral 1, a dificuldade dos alunos frente a conteúdos matemáticos básicos é apontada como uma das principais causas para sua ocorrência, fato que se evidencia nas pesquisas de Rehfeldt et al.(2012), Santarosa e Moreira (2011), Cavasotto e Viali (2011), Sarubbi e Soares (2009), Cury e Bisognin (2006), Cury $(2005,2000)$, Cury e Cassol (2004). Muitas vezes, essas dificuldades indicam que tais conteúdos não foram aprendidos significativamente. Assim, o objetivo deste estudo é apontar, perante a teoria da Aprendizagem Significativa de Ausubel, os Mapas Conceituais como uma alternativa a ser explorada na disciplina a fim de tornar o processo ensino-aprendizagem do Cálculo Diferencial e Integral 1 mais eficaz, de modo a proporcionar uma possibilidade para que ocorra a aprendizagem significativa.
\end{abstract}

Palavras-chave: Aprendizagem significativa, Mapas conceituais, Cálculo diferencial e integral 1.

\section{Abstract \\ Use of concept maps in the Integral and Diferential Calculus courses: in search of meaningful learning strategy}

Necessarily relations among education, society and school involve challenges issues, like school failure. Particularly, in order to understand students' failure in Integral and Diferential Calculus courses, it's found the students' gap in some topics in basic maths as found by some researchers, like Rehfeldt et al. (2012), Santarosa e Moreira (2011), Cavasotto e Viali (2011), Sarubbi e Soares (2009), Cury e Bisognin (2006), Cury (2005, 2000), Cury e Cassol (2004). Frequently this difficulty indicates that such subjects were no learned significantly. Thus, the aim of this work is to show how concept maps, using the meaningful learning theory of Ausubel, can help the teaching-learning process in Integral and Diferential Calculus courses, helping students to have a meaningful learning. Calculus.

Keywords: Meaningful learning, Concept maps, Integral and Diferential 


\section{Introdução}

Nas últimas décadas o número de reflexões envolvendo temas relacionados a Educação Matemática tem aumentado consideravelmente. O mau desempenho dos alunos, em todos os níveis, na Matemática tem suscitado discussões que buscam apontar caminhos para que ocorra uma melhora, tanto no ensino quanto na aprendizagem, dos conteúdos relacionados às áreas deste conhecimento.

No Ensino Superior as disciplinas da área de Matemática carregam consigo o estereótipo de possuírem elevado grau de dificuldade e abstração; preconcepção que tem se perpetuado ao longo dos anos, gerando uma ideia equivocada de que as mesmas afastam-se demasiadamente da realidade dos alunos, não apresentando, portanto, significado algum para os acadêmicos.

Neste universo, enquadra-se o Cálculo Diferencial e Integral $1^{1}$, uma disciplina introdutória de vários cursos, considerada básica porque visa ofertar sólida formação em relação a conteúdos gerais que, por sua vez, sustentarão aprendizagens posteriores em disciplinas específicas.

A respeito da abrangência e importância do estudo de Cálculo, Lopes (1999, p.125) faz uma reflexão afirmando que:

"O Cálculo Diferencial e Integral permite, nas mais variadas áreas do conhecimento, como Engenharia, Química, Física, Biologia, Economia, Computação, Ciências Sociais, Ciências da Terra, etc, a análise sistemática de modelos que permitem prever, calcular, otimizar, medir, analisar o desempenho e performance de experiências, estimar, proceder análises estatísticas e ainda desenvolver padrões de eficiência que beneficiam o desenvolvimento social, econômico, humanístico dos diversos países do mundo".

Assim, indiretamente o Cálculo é essencial para que problemas das mais diversas áreas de conhecimento possam ser resolvidos, o que justifica seu ensino.

Entretanto, o desempenho dos acadêmicos frente a essa disciplina tem se revelado insatisfatório, gerando excessivo número de reprovações, fato que motivou a realização de estudos, como os desenvolvidos por Garzella (2013), Rehfeldt et al (2012), Santos e Matos (2012), Cavasotto e Viali (2011), Menestrina e Moraes (2011), Cury e Bisognin (2006), Cury (2005, 2000), Cury e Cassol (2004), Barbosa (2004), Rezende (2004), Soares de Mello, Soares de Mello e Fernandes (2001), Lopes (1999), Silva e Neto (1995) e Barbosa (1994) que buscam desvelar o que está por trás desta problemática.

${ }^{1}$ Também denominado, simplesmente, de Cálculo 1.

R. B. E. C. T., vol 8, Ed. Sinect, jan-abr.2015 ISSN - 1982-873X

DOI: Em andamento. 
Convém ressaltar que as dificuldades encontradas frente à disciplina de Cálculo 1 não representam a situação particular de uma instituição, fato evidenciado no discurso de Rezende (2004, p.22) quando este coloca que:
"o problema relativo ao ensino de Cálculo se apresenta na grande maioria das universidades brasileiras. Engana-se porém quem acredita que o problema é cultural e/ou específico do sistema educacional brasileiro. Em verdade, o problema vai além de nossas fronteiras e se encontra presente também no âmbito educacional dos países "desenvolvidos".

Dentre os vários fatores que contribuem para o insucesso de diversos alunos neste componente curricular um deles é apontado nas pesquisas com maior ênfase: a carência de conhecimentos matemáticos relativos aos níveis fundamental e médio, considerados essenciais para a abordagem dos conteúdos de Cálculo Diferencial e Integral 1. Esta carência pode ser fruto do distanciamento existente entre os níveis de ensino, em que as conexões entre os conhecimentos adquiridos no Ensino Básico com os abordados no Ensino Superior praticamente não são mencionadas, conforme relata Barbosa (1994, p.02):

"certamente, a falta de elo, de um relacionamento maior entre os níveis de ensino, principalmente entre o nível secundário e o universitário, tem trazido grandes dificuldades na relação ensino-aprendizagem dos alunos que fazem a disciplina de Cálculo Diferencial e Integral I".

Corroboram tal afirmação Cury e Cassol (2004, p.33), ao pontuarem que "a transição para o ensino superior está trazendo dificuldades para alunos e professores, pois muitos estudantes apresentam lacunas em termos de conhecimentos pré-requisitos".

Em muitos casos, essa falta de bagagem matemática, que deveria ter sido adquirida pelo aluno em seu percurso escolar, é reflexo de uma aprendizagem mecânica, que de acordo com Moreira (2010, p.5) "é bastante estimulada na escola, serve para "passar" nas avaliações, mas tem pouca retenção, não requer compreensão e não dá conta de situações novas". E tratando-se de Matemática, para dar conta de situações novas, é necessário ter uma base bem estruturada sobre conhecimentos "velhos".

Sob este aspecto, Lopes (1999, p.125) reforça que:

"o conhecimento matemático é em camadas que se superpõem. Você começa a aprender Matemática no primeiro ano da escola. Se você não sabe dividir, não vai saber o que é uma taxa, se você não sabe o que é uma taxa não vai saber o que é uma derivada e assim por diante. Essa é talvez uma das principais razões porque existem tantas reprovações em Cálculo em nossas universidades. Em muitos casos, os estudantes universitários não sabem os 
conceitos matemáticos anteriores que são necessários para fazer os cursos de Cálculo".

Esta lógica de dependência estrita dos conhecimentos matemáticos, em que um novo conceito é desencadeado a partir de outros conhecimentos anteriores que os amparam, vai ao encontro da Teoria da Aprendizagem Significativa proposta por Ausubel. Segundo ele, a aprendizagem de uma nova informação só ocorre de maneira significativa se partir de outros conhecimentos que o aluno traz consigo. Além disso, ressalta-se que essa aprendizagem pode ser facilitada através da utilização de estratégias adequadas.

Portanto, faz-se necessário desenvolver algumas estratégias para que os alunos superem as dificuldades oriundas da escola, bem como promover outras que possibilitem aos acadêmicos perceber as relações entre os conteúdos de Cálculo 1 com aqueles que serão abordados nas disciplinas específicas, afinal, segundo Silva e Neto (1995, p.04)

"a experiência tem mostrado que, quando os alunos percebem que os conteúdos correspondem às suas expectativas, isto é, conseguem relacioná-los a prováveis situações reais a serem vivenciadas no futuro, quase sempre procuram assimilar os conhecimentos transmitidos e a desenvolver habilidades com maior rapidez".

Dessa forma, sob a ótica Ausubeliana da Aprendizagem Significativa, este estudo tem o intuito de apresentar os Mapas Conceituais como uma dessas estratégias facilitadoras para tornar mais eficaz o processo de ensino-aprendizagem dos conteúdos de Cálculo Diferencial e Integral 1, almejando, de fato, a ocorrência de uma aprendizagem significativa, definida resumidamente por Moreira (2010, p.6) como uma "aprendizagem com significado, compreensão, sentido, capacidade de transferência."

Nesse sentido, acredita-se que, "o uso de Mapas Conceituais pode estimular e organizar a criação e a comunicação de idéias complexas, propiciando uma aprendizagem significativa e, assim, tornando-se uma estratégia possível para a melhoria do ensino/aprendizagem". (MAFFRA, 2011, p.16)

Ressalta-se que professores e alunos podem lançar mão dessa estratégia, uma vez que a mesma permite organizar os conceitos que são mais relevantes no Cálculo, bem como fazer conexões importantes entre seus significados. Sendo assim, este artigo destacará as potencialidades dos Mapas Conceituais quando considera-se esses dois vieses: a elaboração pelos docentes e pelos discentes da disciplina de Cálculo Diferencial e Integral 1. 


\section{Desafios no processo de ensino-aprendizagem de Cálculo 1}

As dificuldades encontradas no processo de ensino-aprendizagem de Cálculo Diferencial e Integral 1, tem sido foco de diversas pesquisas que abordam este tema sob diferentes pontos de vista, buscando analisar os fatores que interferem neste processo.

Dentre eles, o realizado por Garzella (2013) alerta que a prática pedagógica é um dos principais determinantes do sucesso ou fracasso na disciplina, uma vez que as posturas e práticas adotadas pelo professor podem auxiliar ou dificultar o processo de apropriação do conhecimento, logo terão impactos na aprendizagem.

Corrobora em parte essa concepção o trabalho de Barbosa (2004, p.84), no qual uma das conclusões obtidas foi que "o sistema didático na qual a disciplina está ancorada é um fator determinante para o insucesso do aluno na disciplina de Cálculo Diferencial e Integral [...]".

Numa outra perspectiva, aponta-se a carência em relação a conteúdos matemáticos dos níveis fundamental e médio, como fator determinante para a falta de êxito na disciplina.

Em relação a isto, as pesquisadoras Santos e Matos (2012, p.461) destacam que:

"Um ponto bastante observado com relação à grande maioria dos alunos recém-chegados na Universidade, diz respeito aos assuntos tratados nas aulas de Cálculo, que parecem desconhecidos, chegando-se a pensar que muitos alunos não tiveram ou não assimilaram o mínimo de conhecimento dos conteúdos necessários, conteúdos estes que, na sua grande maioria, são repetições do que estudaram na educação básica".

Nesta mesma perspectiva, Cury e Cassol (2004, p.29) afirmam que as dificuldades em relação à matemática básica estão cada vez mais evidentes. Segundo as pesquisadoras,

"a análise dos erros cometidos pelos estudantes, em provas ou em trabalhos de sala de aula, mostra que os estudantes não dominam conteúdos de Álgebra e Geometria do ensino fundamental, bem como os relativos a Trigonometria e Geometria Espacial, do ensino médio. Esse problema, somando-se a dificuldades de abstração e generalização, leva muitos alunos a reprovar na disciplina ou evadir-se dos cursos da área de Ciências Exatas".

Corrobora tal afirmação um estudo desenvolvido por Cavasotto e Viali (2011) envolvendo a análise de erros, bem como uma investigação, realizada por Sarubbi e Soares (2009) a partir da metodologia de resolução de problemas. Neste último estudo, os pesquisadores relatam que "as deficiências trazidas da álgebra, da aritmética, da geometria plana e espacial contribuem para o insucesso também em problemas no ensino superior em disciplinas como o Cálculo Diferencial e Integral." (p.04) 
Numa perspectiva similar, a conclusão obtida por Rehfeldt et al.(2012, p.29) em uma pesquisa que almejava determinar os conhecimentos prévios dos alunos matriculados na disciplina de Cálculo foi que:

"os mesmos possuem, em geral, poucos conhecimentos prévios acerca das propriedades dos logaritmos, do uso das relações trigonométricas e dos cálculos com potências e raízes [...] esses conhecimentos são imprescindíveis para os cursos de engenharia, uma vez que se constituem base para ancorar os novos conhecimentos relativos ao Cálculo I".

Amparada pelos estudos que desenvolveu ao longo dos anos, com alunos de Cálculo 1, Cury $(2005$, p.03) relata que:

"os maiores problemas do ensino de Cálculo são detectados em turmas de calouros, pois há muita diferença entre a forma como os alunos estudam Matemática na Educação Básica - muitas vezes com apelo a "macetes" para decorar fórmulas e regras - e a compreensão dos conceitos básicos de disciplinas matemáticas do ensino superior [...]".

Tal afirmação indica que muitas dificuldades de aprendizagem apresentadas pelos alunos em Cálculo decorrem de uma formação básica deficitária, fruto de uma aprendizagem mecânica, baseada na decoreba, portanto com prazo de validade fixado, uma vez que não é sólida e praticamente não traz significado algum para o aluno.

Dessa forma, pelos trabalhos apontados verifica-se a necessidade eminente de que novas estratégias de ensino na abordagem do Cálculo 1 possam ser utilizadas a fim de sanar as dificuldades que se colocam neste período de transição, afinal, " é nesse instante, frente a essa nova realidade, que os alunos deixam transparecer a fragilidade dos conhecimentos e habilidades supostamente apreendidos na escola básica." (SILVA e NETO, 1995, p.01)

Assim, frente à defasagem de conhecimentos matemáticos considerados pré-requisitos ao Cálculo, Cury e Bisognin (2006, p.02) reforçam que:

"os docentes dessa disciplina precisam detectar, em cada turma, as necessidades mais urgentes e encontrar estratégias de revisão desses conteúdos básicos, haja vista que o Cálculo é ferramenta para a maior parte dos conteúdos das disciplinas do currículo específico das engenharias."

Essas estratégias devem partir dos conhecimentos prévios dos alunos a fim de possibilitar a ocorrência de uma aprendizagem significativa, visto que, a aprendizagem unicamente memorística é extremamente prejudicial nesta área, pois impede a retenção de importantes informações necessárias a médio e longo prazo para dar suporte a novos conhecimentos que serão introduzidos em disciplinas subsequentes ao Cálculo. 


\section{Teoria da Aprendizagem Significativa: alguns conceitos importantes}

O médico e psicólogo David Paul Ausubel (1968), foi o precursor da Teoria da Aprendizagem Significativa, uma teoria cognitiva de aprendizagem.

Segundo o entendimento de Moreira e Masini (1982, p.03), a linha cognitivista da psicologia "preocupa-se com o processo da compreensão, transformação, armazenamento e o uso da informação envolvida na cognição, e tem como objetivo identificar padrões estruturados dessa transformação."

Assim, entende-se que Ausubel buscava descrever e explicar os mecanismos pelos quais se dava a aquisição, a assimilação e a retenção de um conjunto de significados associados aos conhecimentos do contexto escolar, na estrutura cognitiva do aluno. Esta é definida como "conteúdo total de ideias de um indivíduo e sua organização, ou o conteúdo e a organização de suas ideias, em uma determinada área de conhecimento" (Moreira, 2012, p.01) e está sempre em processo de mutação.

A teoria Ausubeliana, cujo foco é o aluno, tem como principal conceito a Aprendizagem Significativa, definida como o processo pelo qual um novo conhecimento interage e se incorpora de maneira não literal e não arbitrária a conhecimentos relevantes existentes na estrutura cognitiva do aprendiz, ou seja, a conhecimentos prévios existentes, denominados subsunçores.

Assim, o pressuposto básico defendido por Ausubel é que a aprendizagem somente se concretiza se partir de conhecimentos relevantes que o aprendiz carrega consigo, portanto o conhecimento prévio é a variável mais importante, isto é, que mais influencia a aprendizagem. Obviamente, neste contexto é primordial que exista uma pré-disposição do aprendiz em aprender.

Dito de outra maneira, a aprendizagem significativa acontece quando o aluno se dispõe em fazer interações substanciais entre os novos conhecimentos a serem aprendidos e os conhecimentos relacionados a estes já existentes em sua estrutura cognitiva. Esse processo de interação entre os subsunçores e a nova informação é denominado na teoria ausubeliana de assimilação. Um processo que, segundo Maffra (2011, p.15), "promove integração entre conceitos, de tal modo que os conceitos novos interagem com os já existentes na estrutura cognitiva do aprendente, integrando o novo material e, ao mesmo tempo, modificando-os".

Moreira (2012, p.14) esclarece que, na aprendizagem significativa, a assimilação pode se dar através de três formas: por subordinação, superordenação ou de modo combinatório.

Na primeira, as novas informações adquirem significado por um processo de "ancoragem" a subsunçores relevantes, mais gerais e inclusivos existentes na estrutura cognitiva do aprendiz; o

182 DOI: Em andamento.

R. Bras. de Ensino de C\&T 
novo conceito aprendido encontra-se, portanto, subordinado a estes, por este motivo denominase aprendizagem subordinada.

Na aprendizagem superordenada o novo conhecimento é mais geral e inclusivo. Este é obtido a partir da abordagem de conceitos ou proposições relacionados a ele, existentes na estrutura cognitiva do aprendiz e sua aquisição envolve processos de abstração, indução e síntese. Após alcançado, esse novo conhecimento passa a subordinar aqueles que the originaram.

E por último, a aprendizagem é dita combinatória se um novo conceito, aprendido a partir das interações com vários conhecimentos prévios, não é subordinado a nenhum outro, mas também não é tão geral e inclusivo, que possa subordinar algum conhecimento específico, ou seja, tem alguns atributos criteriais, alguns significados comuns a eles, mas não os subordina nem superordena. (MOREIRA, 2012, p.16)

Cabe ainda ressaltar que, à medida em que essas interações vão se desenvolvendo, os significados que constituíam os conhecimentos prévios tornam-se mais férteis, elaborados, refinados e diferenciados, adquirindo portanto maior solidez ou estabilidade, e reorganizando-se na estrutura cognitiva do aprendiz. Esse encadeamento, em que os subsunçores modificam-se gradativamente e assumem determinada hierarquia, engloba dois processos concomitantes que Ausubel denominou diferenciação progressiva e reconciliação integradora.

$\mathrm{Na}$ sequência deste estudo parte destes conceitos da teoria ausubeliana serão exemplificados através de conteúdos que remetem à disciplina de Cálculo Diferencial e Integral 1.

\section{Ensino de Cálculo $x$ Aprendizagem Significativa: uma aproximação possível}

O ensino do Cálculo 1 fundamenta-se no estudo de funções. São elas que darão suporte a todos os conteúdos trabalhados nesta disciplina - limites, derivadas e integrais - e em disciplinas subsequentes: Cálculo 2, Cálculo 3, Física, Equações Diferenciais.

O aluno tem seu primeiro contato com funções no primeiro ano do Ensino Médio, assim, quando este ingressa no Ensino Superior, mais especificamente na disciplina de Cálculo Diferencial e Integral 1, o docente espera que o mesmo possua conhecimentos anteriores relevantes em sua estrutura cognitiva (subsunçores), de modo que seja possível fazer a aproximação destes com os novos conhecimentos.

Como consequência desta expectativa, "é de praxe tratar o aluno iniciante como se ele se apresentasse em condições ideais a acomodar novos conhecimentos num grau bem superior de abstração, sem antes passar por aqueles mais sensíveis que digam respeito à sua realidade prática." (SILVA e NETO, 1995, p.03)

Todavia, nem sempre os acadêmicos encontram-se nas condições almejadas pelos

DOI: Em andamento. 
professores. Dessa forma, Silva e Neto $(1995$, p.03) sugerem que, no primeiro contato com o corpo discente,

\begin{abstract}
"talvez fosse mais sensato optar pela apresentação de conceitos tidos como indispensáveis à compreensão e solução dos problemas, de modo que o mesmo pudesse perceber suas relações com outras questões e conceitos já existentes na sua estrutura mental, ou seja, manter sempre presente a interligação entre os novos dados e aqueles disponíveis na memória".
\end{abstract}

Neste sentido, na apresentação da disciplina de Cálculo, pode-se colocar aos alunos que muitos fenômenos reais são descritos por modelos matemáticos, que por sua vez podem ser expressos através de uma fórmula algébrica, ou seja, de uma função matemática. Os modelos matemáticos permitem realizar previsões e extrair importantes informações a respeito do fenômeno; informações que também podem ser obtidas a partir do estudo de limites e derivadas da função. Entretanto, para que seja possível a abordagem de limites e derivadas é necessário que o aluno tenha conhecimento prévio sobre funções, isto é, a abordagem dos conteúdos do Cálculo requer a interação substancial com os subsunçores referentes à funções de uma variável real.

Neste processo, cada aluno pode ter conhecimentos prévios distintos, uma vez que o que é relevante para um pode não ser relevante para outro. Alguns alunos poderão fazer associações com os diagramas de Venn (ou das setas), outros com plano cartesiano utilizado para a representação gráfica, outros com a existência de "regras" que seriam as leis de formação. Alguns alunos talvez não lembrem de nada a respeito do tema.

Neste caso, quando ocorre a perda de diferenciação entre os significados do conceito, dizemos que houve uma obliteração, definida por Moreira (2012, p.04) como "um processo normal do funcionamento cognitivo, é um esquecimento, mas em se tratando de aprendizagem significativa a reaprendizagem é possível e relativamente rápida."

Assim, o primeiro desafio do professor é desenvolver a sensibilidade para tentar identificar (ou resgatar) os diferentes subsunçores, e o segundo é implementar estratégias que permitam introduzir o novo conceito a partir dos conhecimentos prévios identificados, de modo que possa se dar uma aprendizagem significativa.

Nesse sentido, Cury e Cassol (2004, p.34), mencionam ser, "necessário mudar a metodologia de trabalho, encontrando alguma forma de desafiar os estudantes, propondo atividades motivadoras, que lhes despertem o interesse pelo estudo, pela realização das tarefas propostas, pelo monitoramento de sua própria cognição".

Ressalta-se que, ao aprender significativamente um novo conceito, por exemplo limites, 
as informações referentes à funções (conceito, domínio, imagem, condições de existência, formas de representação, propriedades operatórias) serão reorganizadas na estrutura cognitiva do aluno, uma vez que terão um novo significado, mais abrangente, desencadeado a partir das constantes interações realizadas com as novas informações introduzidas.

$\mathrm{Na}$ aprendizagem significativa, este processo ocorre continuamente. Portanto, Moreira (2012, p.02) esclarece que:

"O subsunçor pode ter maior ou menor estabilidade cognitiva, pode estar mais ou menos diferenciado, ou seja, mais ou menos elaborado em termos de significados. Contudo, como o processo é interativo, quando serve de idéiaâncora para um novo conhecimento ele próprio se modifica adquirindo novos significados, corroborando significados já existentes".

Consequentemente, a partir do momento que o conceito de limite existir na estrutura cognitiva do aluno ele servirá de subsunçor para novas informações referentes ao conceito de derivada e, por sua vez, mediante novas interações realizadas, o conceito "limite" sofrerá uma ressignificação e reorganização em sua estrutura cognitiva.

Ainda em relação aos subsunçores, Moreira (2012, p.05), ressalta que há subsunçores que são hierarquicamente subordinados a outros, entretanto essa hierarquia pode alterar-se se um novo conceito passar a ser tão abrangente a ponto de incorporar outros, isto é, a subordinar os conhecimentos prévios. Neste caso, o novo conhecimento assume o topo da pirâmide em termos de importância hierárquica.

Ao ter o primeiro contato com funções, por exemplo, talvez o aluno acreditasse que este era o conhecimento com maior hierarquia em relação aos subsunçores que possuía: noção de conjuntos, conjuntos numéricos, operações entre conjuntos, relações, equações, inequações, plano cartesiano. Além disso, todos os tipos de função estudadas: afim, quadrática, modular, exponencial e logarítmica estavam subordinadas e satisfaziam certas condições e propriedades ligadas a um conceito maior que era o conceito de função. Assim, dizemos que ocorreu a aprendizagem subordinada.

Para o estudante que tiver contato com a disciplina de Cálculo Diferencial e Integral 1 ainda que a ênfase seja restrita, uma vez que o espaço considerado engloba apenas o conjunto dos números reais - a noção de função se ampliará quando este aprender que limites, derivadas e integrais também são exemplos de funções. Na mesma lógica, ao estudar Cálculo de várias variáveis e Álgebra Linear, em que os conjuntos considerados incluem dimensões maiores (às vezes infinitas), o conceito de função será abordado sob uma nova perspectiva, mais abrangente que as anteriores, de modo que o conhecimento do aluno será novamente ampliado. Determinantes e matrizes também serão apresentados como funções e esta informação certamente foge do escopo introduzido no Ensino Médio e com o qual os acadêmicos estavam 
acostumados a trabalhar: considerando função como uma relação entre conjuntos numéricos.

Portanto, à medida em que outros exemplos de função forem introduzidos, o aluno poderá adquirir um novo conhecimento, que abarcará uma gama de conhecimentos preexistentes, e portanto este será hierarquicamente superior. Nesse caso, dizemos que ocorreu a aprendizagem superordenada.

Há ainda de se considerar que a estrutura cognitiva pode ser caracterizada por dois processos: a diferenciação progressiva e a reconciliação integradora.

No exemplo mencionado anteriormente, a respeito das diferentes abordagens de funções de acordo com o nível de ensino do aluno, evidencia-se a diferenciação progressiva, definida como "o processo de atribuição de novos significados a um dado subsunçor (um conceito ou uma proposição, por exemplo) resultante da sucessiva utilização desse subsunçor para dar significado a novos conhecimentos." (MOREIRA, 2012, p.06)

Neste processo, simultaneamente a diferenciação progressiva, vai ocorrendo na estrutura cognitiva do aprendiz, a reconciliação integradora, "que consiste em eliminar diferenças aparentes, resolver inconsistências, integrar significados, fazer superordenações." (MOREIRA, 2012, p.06)

Um outro exemplo que elucida a diferenciação progressiva e a reconciliação integradora envolve o significado da expressão $\mathrm{x}=1$. Inicialmente, ao trabalhar no espaço dos números reais, essa expressão representa um ponto na reta real. Num segundo momento, ao trabalhar no espaço RxR, a expressão $x=1$ passa a representar uma reta. Num terceiro momento, no espaço RxRxR tal expressão representa um plano.

As diferenciações e especificidades que envolvem os conceitos, muitas são sutis. Entretanto, por trás dessas aparentes sutilezas existe um emaranhado de conhecimentos que permitem realizar essas diferenciações, esmiuçando as particularidades de cada caso. Todavia, para que seja possível realizar tais diferenciações, enfatiza-se novamente a necessidade de que o aluno apresente subsunçores relevantes em sua estrutura cognitiva.

Mas o que fazer quando o aluno não possui os conhecimentos prévios adequados? Neste caso, Moreira (2012, p.10) propõe que se faça uso dos organizadores prévios, dentre os quais encontra-se os mapas conceituais.

\section{Mapas conceituais na abordagem de Cálculo}

Quando o aluno não apresenta os subsunçores adequados e suficientemente estáveis para realizar a ancoragem do novo conhecimento, ou quando estes estão "desativados", Moreira (2012, p.11) sugere que essa situação seja contornada através da utilização de organizadores prévios: "recurso instrucional apresentado em um nível mais alto de abstração, generalidade e 
inclusividade em relação ao material de aprendizagem" e que serve para manipular a estrutura cognitiva do aprendiz.

Ainda segundo o autor, se os conhecimentos prévios necessários inexistem a melhor alternativa é promover a sua construção antes de introduzir as novas informações. Caso existam, o organizador prévio desempenha o papel de "ponte cognitiva" entre o que o aluno sabe e o que necessita saber, uma vez que permite mostrar a relacionalidade e discriminabilidade entre a nova informação e os subsunçores, algo que muitas vezes os alunos não conseguem, a priori, perceber. Portanto, sua utilização é indicada para as duas situações.

Mas, no âmbito da aprendizagem significativa, o que pode ser considerado um organizador prévio?

Para Luz (2010, p.25), organizador prévio é:

"todo o material instrucional introdutório que apresente e organize de uma forma abrangente os conceitos e ideias mais gerais e inclusivos necessários à aprendizagem significativa do próximo tópico de estudo, e se facilitam a interação substancial e não arbitrária tornando os novos materiais potencialmente significativos para o aprendiz, podem ser considerados como organizadores prévios".

Entende-se que, por ser apresentado inicialmente num nível de maior abrangência, o organizador prévio permitirá que o aluno perceba que as novas informações estão associadas, de alguma forma, aos conhecimentos prévios que ele detém.

No contexto do Cálculo Diferencial e Integral 1, um recurso que pode ser explorado e tem sido utilizado como organizador prévio, é o Mapa Conceitual.

Em síntese, os mapas conceituais foram introduzidos pelo norte americano Joseph Novak, por volta da década de 70. Mais precisamente, em 1972 o professor Novak utilizou pela primeira vez esta ferramenta, que tinha como objetivo representar graficamente a compreensão de conceitos das crianças, a fim de que a evolução do conhecimento pudesse ser acompanhada e entendida. Eles são definidos como, "diagramas que indicam relações entre conceitos (apenas conceitos) e procuram refletir a estrutura conceitual de um certo conhecimento. Mais especificamente, podem ser vistos como diagramas conceituais hierárquicos." (MOREIRA, 2010, p.06)

Essa estruturação hierárquica, permite perceber tanto os desdobramentos de um determinado conceito (diferenciação progressiva) quanto a relações com outros conceitos (reconciliação integradora), permitindo uma melhor aprendizagem para o aluno.

Em particular, na construção de mapas conceituais pelo docente para abordagem de um conteúdo em sala, o princípio da reconciliação integradora, auxilia o professor, visto que, 
conforme pontuam Jesus e Silva (2004, p.03) este princípio:

"estabelece as ligações entre idéias semelhantes assim como as suas diferenças, dando ao aluno uma visão global do assunto estudado, sem que este fique dividido em tópicos sem aparente relação entre eles. Além disso, pode estabelecer relações entre o conteúdo que acabou de ser exposto e idéias apresentadas anteriormente e também com idéias que ainda serão apresentadas".

Para Frota (2004, p.17), as "representações visuais, ainda que não convencionais, poderiam ser um bom começo para se avançar, com vistas a construções de conceitos tão complexos quanto os de funções, limites, continuidade, derivadas, integrais."

Cabe ainda ressaltar que esta ferramenta não é destinada exclusivamente ao professor. Ela pode (e deve) ser formulada tanto por docentes quanto por discentes. Ou seja, pode ser utilizada com instrumento de ensino ou aprendizagem. Neste segundo caso, Moreira (2010) reforça que, os processos envolvidos na elaboração dos mapas conceituais - construção, negociação, apresentação, reformulação - são altamente facilitadores de uma aprendizagem significativa.

No que compete à disciplina de Cálculo Diferencial e Integral 1, conforme fora mencionado anteriormente, em geral, o aluno não tem maturidade para perceber que conceitos prévios são relevantes para a abordagem de determinado tema e tão pouco consegue perceber quais as relações desses conceitos com a nova informação introduzida.

Nesse sentido, enquanto recurso para aprendizagem de um novo tópico, a construção de mapas conceituais pode elucidar para o aluno as lacunas que precisam ser preenchias ou quais são os obstáculos de entendimento que ele possui em torno deste conteúdo; isso possibilita que o mesmo procure sanar suas dificuldades, uma vez que as mesmas, "se não resolvidas ainda nesta etapa, comprometem a aprendizagem ao longo de toda a graduação." (SANTAROSA E MOREIRA, 2011, p.322)

Essa via de mão dupla entre a construção dos mapas e busca de soluções para as dúvidas levantadas, permitirá que os discentes construam seus conhecimentos de forma significativa e também tomem consciência dos avanços realizados neste processo. Dessa forma, " o aluno que desenvolver essa habilidade de construir seu mapa conceitual enquanto estuda determinado assunto, está se tornando capaz de encontrar autonomamente o seu caminho no processo de aprendizagem." (TAVARES, 2007, p.74)

Para o Tavares (2007, p.75), se o aluno conseguir ter clareza sobre as suas perguntas, ou suas dúvidas, ele já terá encaminhado a sua aprendizagem de maneira conveniente e segura, uma vez que é mais fácil ele procurar ajuda quando está ciente das dificuldades que possui. 
Enquanto ferramenta de ensino, os mapas conceituais podem ser elaborados para um curso, uma disciplina, um conteúdo ou um tópico específico.

Sob este aspecto, a utilização de mapas pelos docentes para explorar determinado conteúdo ou ilustrar o programa da disciplina de Cálculo 1, por exemplo, pode auxiliar os alunos a perceberem que os conceitos envolvidos não estão desvinculados uns dos outros, ao contrário, em geral se conectam e se complementam.

Dessa forma, pode-se amenizar um aspecto considerado por Menestrina e Moraes (2011, p.01) como contradição no processo educativo, especialmente no que compete ao planejamento e avaliação: "a fragmentação dos conteúdos sem que o aluno perceba a noção do todo."

Os mapas conceituais também possibilitam que o professor perceba quais são os principais conceitos que precisam ser abordados, e podem servir como ferramenta para acompanhamento da aprendizagem dos alunos.

Além disso, a interação entre os envolvidos no processo de ensino-aprendizagem (professores e alunos), bem como a relação desses com o objeto de estudo (conhecimento) pode ser facilitada com a utilização dessa ferramenta, pois um novo conceito pode ser introduzido dentro de um diagrama visual organizado, a partir de discussões e conclusões obtidas em sala, em conjunto, durante o processo educativo.

$\mathrm{Na}$ sequência, apresentamos alguns exemplos de mapas conceituais relacionados à disciplina de Cálculo Diferencial e Integral 1, que podem ser explorados. 


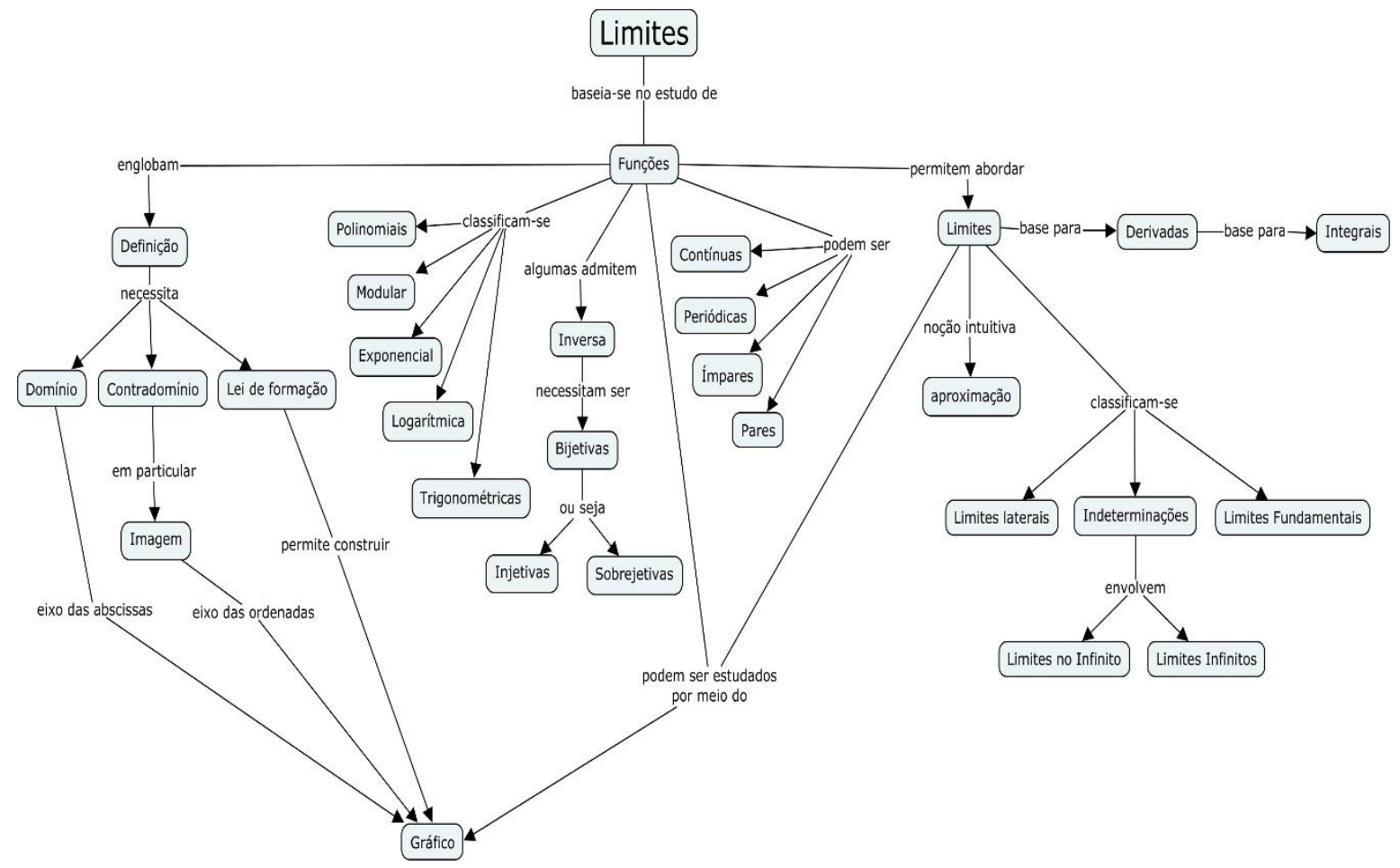

Figura 1 - Mapa conceitual referente ao conteúdo de limites.

(Fonte: próprio autor)

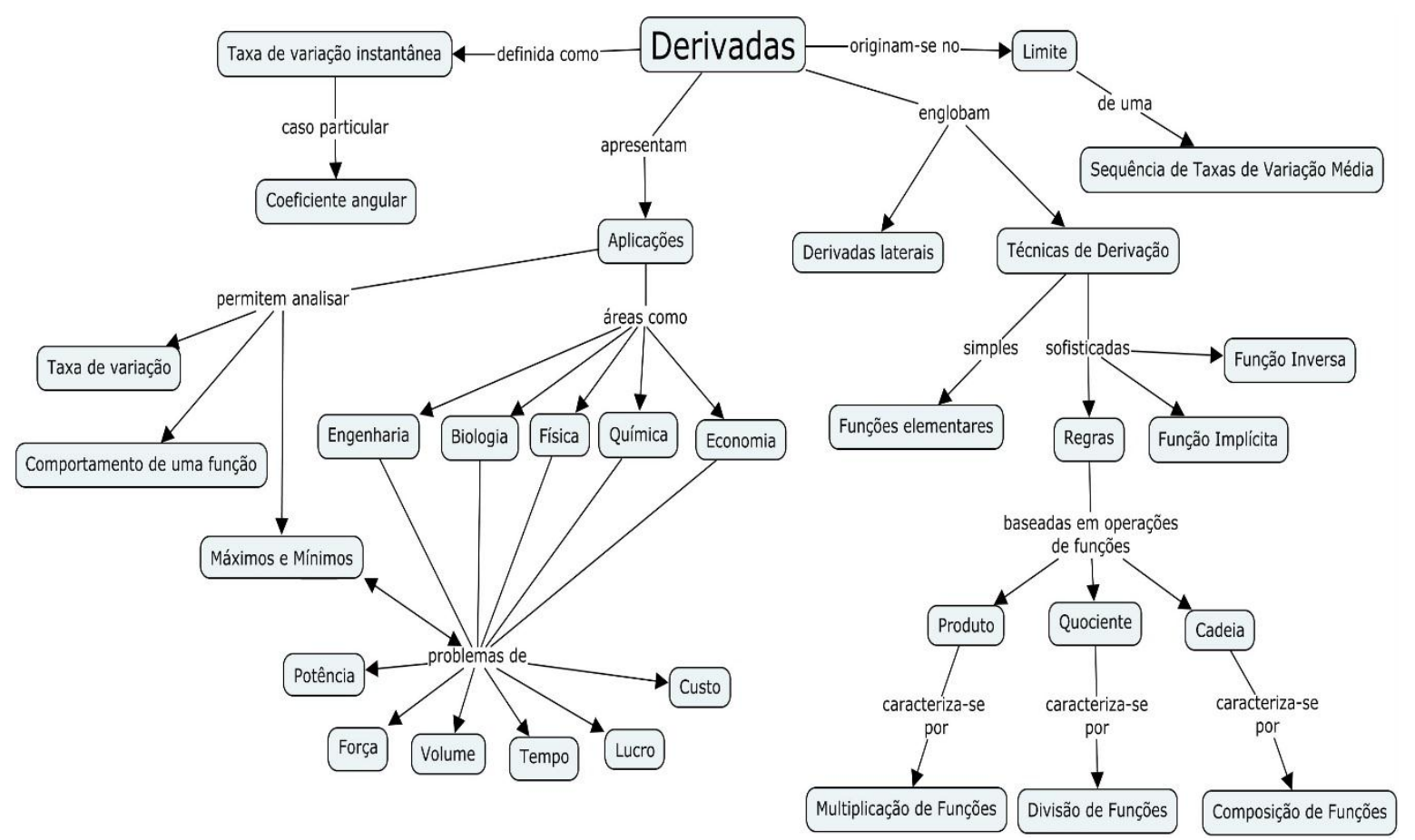

Figura 2 - Mapa conceitual referente ao conteúdo de derivadas.

(Fonte: próprio autor) 


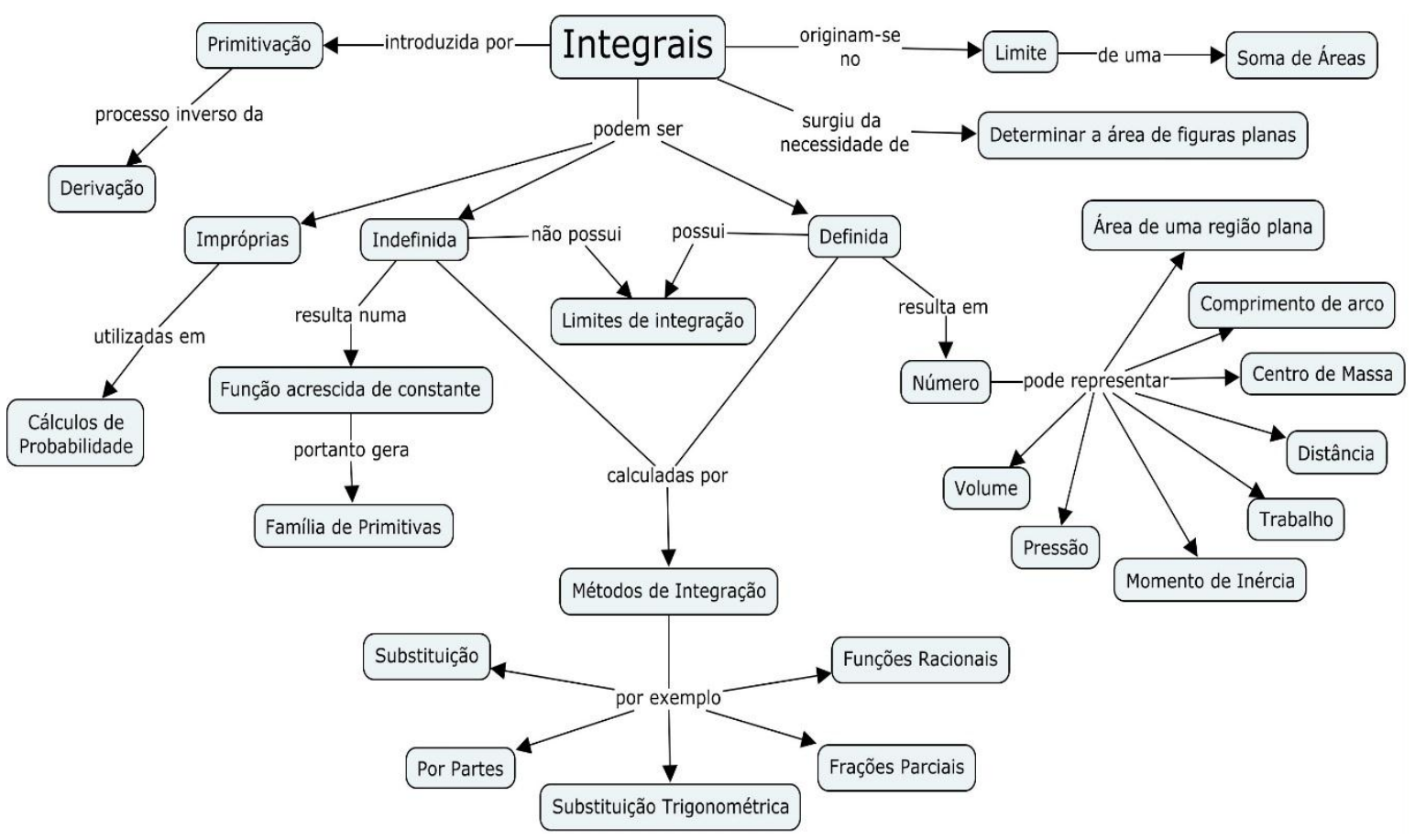

Figura 3 - Mapa conceitual referente ao conteúdo de integrais.

(Fonte: próprio autor)

\section{Considerações finais}

Neste trabalho buscou-se descrever de forma breve como os Mapas Conceituais podem ser utilizados enquanto ferramenta para auxiliar no processo de ensino-aprendizagem da disciplina de Cálculo Diferencial e Integral 1, a fim de que seja proporcionada uma possibilidade para ocorrência da aprendizagem significativa.

Diante do quadro em que se encontra essa disciplina, caracterizado por elevados índices de reprovação em diversas instituições de ensino, se faz necessário repensar as estratégias adotadas, tanto por professores quanto por discentes, frente a esse componente curricular.

Dessa forma, amparados na Teoria da Aprendizagem Significativa que considera que a aprendizagem só ocorre efetivamente se partir dos conhecimentos prévios existentes na estrutura cognitiva dos alunos, os mapas conceituais podem servir como um termômetro, tanto a professores quanto aos alunos, a fim de acompanhar como está se dando a evolução do aprendizado e demonstrar como os conteúdos matemáticos referentes a disciplina estão conectados, numa relação de forte dependência.

Em particular, a construção de mapas conceituais pelos alunos permite que, no processo de buscas e trocas de informações, dificuldades e lacunas sejam identificadas e consequentemente a prática docente seja reformulada, no sentido de esclarecê-las ou preenchêlas.

R. B. E. C. T., vol 8, Ed. Sinect, jan-abr.2015 ISSN - 1982-873X

DOI: Em andamento. 
Portanto, como esse é um processo construtivo, interativo e contínuo, entre professor, aluno e conhecimento, acredita-se que a utilização dessa ferramenta nas aulas pode efetivamente melhorar o processo de ensino-aprendizagem de Cálculo Diferencial e Integral 1.

\section{Referências}

BARBOSA, M. A. O Insucesso no Ensino e Aprendizagem na Disciplina de Cálculo Diferencial e Integral. 2004. 101 f. Dissertação (Mestrado em Educação). Pontifícia Universidade Católica do Paraná, Curitiba, 2004.

BARBOSA, G. O. Raciocínio lógico formal e aprendizagem em Cálculo Diferencial e Integral: o caso da Universidade Federal do Ceará. 1994. 109 f. Dissertação (Mestrado em Educação). Universidade Federal do Ceará, Fortaleza, 1994.

CAVASOTTO, M; VIALI, L. Dificuldades na aprendizagem de cálculo: o que os erros podem informar. Boletim GEPEM, no 59, p.15-33, jul./dez. 2011.

CURY, H. N. Estilos de aprendizagem de alunos de Engenharia. In: XXVIII COBENGE - Congresso Brasileiro de Ensino de Engenharia, 2000, Ouro Preto, Minas Gerais.

CURY, H. N. Aprendizagem em Cálculo: uma experiência com avaliação formativa. In: XXVIII Congresso Nacional de Matemática Aplicada e Computacional. Santo Amaro, 2005.

CURY, H. N.; CASSOL, M. Análise de Erros em Cálculo: uma Pesquisa para Embasar Mudanças. Acta Scientiae, Canoas, Rio Grande do Sul, v. 6, n. 1, p.27-36, jan./jun. 2004.

CURY, H. H.; BISOGNIN, E. Calculando e volume de um sólido: como a análise de erros pode auxiliar professores a elaborar atividade de ensino para calouros de Engenharia. In: XXIV COBENGE - Congresso Brasileiro de Ensino de Engenharia, 2006, Passo Fundo, Rio Grande do Sul. FROTA, M. C. R. Estratégias gráficas na aprendizagem de Cálculo: In: VIII ENEM - Encontro Nacional de Educação Matemática, 2004, Recife. Anais. p.07-20.

GARZELLA, F. A. C. A disciplina de Cálculo I: a análise das relações entre as práticas pedagógicas do professor e seus impactos nos alunos. 2013. 298 f. Tese (Doutorado em Educação) Universidade Estadual de Campinas. São Paulo. 2013.

JESUS, M. A. S; SILVA, R. C. O. A Teoria de David Ausubel - O uso dos organizadores prévios no ensino contextualizado de funções. VII Encontro Nacional de Educação Matemática - 2004. LOPES, A. Algumas reflexões sobre a questão do alto índice de reprovação nos cursos de Cálculo da UFRGS. Sociedade Brasileira de Matemática. Rio de Janeiro, n.26/27, p.123-146, jun./dez. 1999. (Matemática Universitária

LUZ, S. V. Aprendizagem significativa de Função do 10 Grau: uma investigação por meio da 
modelagem matemática e dos mapas conceituais. 2010. 172 f. Dissertação (Mestrado em Educação para a Ciência e o Ensino de Matemática). Universidade Estadual de Maringá. Paraná, 2010.

MAFFRA, S. M. Mapas Conceituais como recurso facilitador da Aprendizagem Significativa Uma abordagem prática. 2011. 129 f. Dissertação (Mestrado em Ensino de Ciências). Instituto Federal de Educação, Ciência e Tecnologia. Rio de Janeiro, 2011.

MENESTRINA, T. C.; MORAES, A. F. Alternativas para uma aprendizagem Significativa em Engenharia: Curso de Matemática Básica. Revista Brasileira de Ensino de Engenharia, v.30, n.1, p.52-60, 2011.

MOREIRA, M. A. O que é afinal aprendizagem significativa? Disponível em < http://www.if.ufrgs.br/ moreira/oqueeafinal.pdf >. Acesso em: 01 agosto 2014.

MOREIRA, M. A. Aprendizaje Significativo Crítico. Indivisa, Boletín de Estúdios e Investigación, 2a edição, no 6, p.83-101, 2010.

MOREIRA, M. A. Organizadores Prévios e Aprendizagem Significativa. Revista Chilena de Educación Científica, v. 7, n. 2, p. 23-30, 2008. Revisado em 2012.

MOREIRA, M. A. Aprendizagem Significativa Crítica. Disponível em: < http://www.if.ufrgs.br/ moreira/apsigcritport.pdf >. Acesso em: 28 julho 2014.

MOREIRA, M. A.; MASINI, E. F. S. Aprendizagem significativa: a teoria de David Ausubel. São Paulo: Moraes, 1982.

REHFELDT, M. J. H.; NICOLINI, C. A. H.; QUARTIERI, M. T.; GIONGO, I. M. Investigando os conhecimentos prévios dos alunos de Cálculo do Centro Universitário Univates. Revista de Ensino de Engenharia, v.31, n.1, p.24-30, 2012.

REZENDE, W. M. O Ensino de Cálculo: um problema do ensino superior de Matemática? Anais do VIII ENEM, Mesa Redonda, Pernambuco, 2004.

SANTAROSA, M. C. P.; MOREIRA, M. A. O Cálculo nas aulas de Física da UFRGS: um estudo exploratório. Investigações em Ensino de Ciências, v. 16(2), p.317-351, 2011.

SANTOS, S. P.; MATOS, M. G. O. O ensino de Cálculo I no curso de Licenciatura em Matemática: obstáculos na aprendizagem. Revista Eventos Pedagógicos, v.3, n.3, p.458-473, ago./dez. 2012.

SARUBBI, P. A.; SOARES, F. Investigando dificuldades de alunos de Cálculo em problemas de taxas relacionadas. In: XXXVII COBENGE - Congresso Brasileiro de Ensino de Engenharia, 2009, Recife, Pernambuco.

SILVA, J. F.; NETO, H. B. Questões Básicas no ensino de Cálculo. Ceará, Artigo Científico/ UFC, 1995. Disponível em: < http://www.multimeios.ufc.br/arquivos/pc/artigos/artigo-questoesbasicas-do-ensino-de-calculo.pdf >. Acesso em: 19 agosto 2014.

R. B. E. C. T., vol 8, Ed. Sinect, jan-abr.2015 ISSN - 1982-873X

DOI: Em andamento. 
SOARES DE MELLO, J. C. C. B; SOARES DE MELLO, M. H. C.; FERNANDES, A. J. S. Mudanças no ensino de Cálculo I: Histórico e Perspectivas. In: XXIX COBENGE - Congresso Brasileiro de Ensino de Engenharia, 2001, Porto Alegre, Rio Grande do Sul.

TAVARES, R. Construindo Mapas Conceituais. Ciência \& Cognição, Rio de Janeiro, vol. 12, p.72-85, 2007.

EDINÉIA ZARPELON - Mestranda do Programa de Pós-Graduação em Ensino de Ciência Tecnologia (PPGECT) da Universidade Tecnológica Federal do Paraná (UTFPR) - Câmpus Ponta Grossa. Professora do Departamento Acadêmico de Matemática e membro do Grupo de Pesquisa em Educação, Ciência e Tecnologia (GPECT) da Universidade Tecnológica Federal do Paraná (UTFPR) - Câmpus Pato Branco. E-mail: ezarpelon@utfpr.edu.br

LUIS MAURICIO MARTINS DE RESENDE - Doutor em Engenharia Mecânica pela Universidade Federal de Santa Catarina (UFSC). Professor do Programa de Pós-Graduação em Ensino de Ciência e Tecnologia (PPGECT) da Universidade Tecnológica Federal do Paraná (UTFPR) - Câmpus Ponta Grossa. E-mail: Imresende@utfpr.edu.br

NILCÉIA APARECIDA MACIEL PINHEIRO - Doutora em Educação Científica e Tecnológica pela Universidade Federal de Santa Catarina (UFSC). Professora do Programa de Pós-Graduação em Ensino de Ciência e Tecnologia (PPGECT) da Universidade Tecnológica Federal do Paraná (UTFPR) - Câmpus Ponta Grossa. E-mail: nilceiaamp@gmail.com 